\title{
Double porosity model to describe both permeability change and dissolution processes
}

\author{
Yuichi NIIBORI*, Hideo USUI* and Taiji CHIDA* \\ *Department of Quantum Science and Energy Engineering, Tohoku University \\ 6-6-01-2, Aza-Aoba, Aramaki, Aoba-ku, Sendai 980-8579, Japan \\ E-mail: yuichi.niiboril@qse.tohoku.ac.jp
}

Received 31 March 2015

\begin{abstract}
Cement is a practical material for constructing the geological disposal system of radioactive wastes. The dynamic behavior of both permeability change and dissolution process caused by a high $\mathrm{pH}$ groundwater was explained using a double porosity model assuming that each packed particle consists of the sphere-shaped aggregation of smaller particles. This model assumes two kinds of porosities between the particle clusters and between the particles, where the former porosity change mainly controls the permeability change of the bed, and the latter porosity change controls the diffusion of $\mathrm{OH}^{-}$ions inducing the dissolution of silica. The fundamental equations consist of a diffusion equation of spherical coordinates of $\mathrm{OH}^{-}$ions including the first-order reaction term and some equations describing the size changes of both the particles and the particle clusters with time. The change of over-all permeability of the packed bed is evaluated by Kozeny-Carman equation and the calculated radii of particle clusters. The calculated result well describes the experimental result of both permeability change and dissolution processes.
\end{abstract}

Key words : Geological disposal, Radioactive waste, Cement materials, Groundwater, Permeability, Dissolution, Diffusion, Porosity

\section{Introduction}

Cement is a key material for constructing the repository system of high level and TRU radioactive wastes. Since the groundwater contacting with cement alters up to 13 in $\mathrm{pH}$, so far Federation of Electric Power Companies of Japan (FEPC) and Japan Nuclear Cycle development institute (JNC) (2005) and JNC (1999) have examined the influences of cement material on the initial condition of the repository system. The results suggested that such hyperalkaline groundwater dissolves silicate and silica minerals around the repository, because the solubility of silicic acid rapidity increases as pH exceeds 9.5: for example, (Iler, 1979, Atkinson, 1985, Stumm and Morgan, 1996). That is, the use of cement for the construction of the repository might induce the increment of permeability around the repository and finally affect the confinement of the radioactive wastes.

Sugiyama et al. (2003), Usui et al., (2004), (2005), Mäder et al. (2006), Narita et al. (2010), Funabashi et al. (2012), Niibori et al. (2012), (2013) and (2014a,b) also have examined the more detail impacts of chemical/physical alteration caused by hyperalkaline groundwater on the migration rates of radionuclides through some barriers of the geological disposal system. Of them, Mäder et al. (2006) carried out the field test by continuously injecting hyperalkaline fluid from a borehole at Grimsel Test Site, Switzerland. In the results, the increment of permeability and the dissolution of silicate or silica minerals were confirmed. However, the relation of permeability change with the dissolution might be not simple in the detail. Besides, Usui et al. (2004) have examined the permeability change of some packed beds, using a high $\mathrm{pH}$ solution $(\mathrm{NaOH}, 0.1 \mathrm{mM})$. They reported that the permeability did not immediately change although the soluble silicic acid was eluted out of the column (a bed packed with silica particles).

It is necessary to quantitatively explain such dynamics of permeation of $\mathrm{NaOH}$ solution into the packed bed of silica particle clusters with the dissolution of silica from the particles. Fig. 1 shows the permeability defined by Darcy's 
law, i.e., $u_{\mathrm{D}}=-\left(k_{\mathrm{H}} / \mu\right) \partial p / \partial x$, where $u_{\mathrm{D}}$ is Darcy fluid flow velocity, $k_{\mathrm{H}}$ is permeability, $\mu$ is viscosity and $\partial p / \partial x$ is pressure gradient. Fraction dissolved, $f$, means the fraction of silicic acid in the bed packed with silica particles. That is, $f=1$ means that the packed particles in a column completely vanish through the dissolution process. Usui et al. (2004) used amorphous silica particles with a size fraction of $74 \mu \mathrm{m}$ to $149 \mu \mathrm{m}$ as a solid phase. Therefore, the secondary pores of particle might affect such a behavior of the permeability of the packed bed. In fact, the BET specific surface area $\left(\mathrm{N}_{2}\right.$ gas) of the particles was $350 \mathrm{~m}^{2} / \mathrm{g}$. Furthermore, as shown in Fig. 1, a simple particle shrinking model was not able to explain both the permeability change and the fraction dissolved, where the permeability was estimated by using Kozeny-Carman equation. Besides, it was confirmed from the change of the packed bed with time, the apparent length of packed bed shortened after the remarkable increment of permeability.

The purpose of the present study is to explain these behaviors using the new double porosity model that assumes two kinds of porosities between the particle clusters and between the particles, where the former porosity change mainly controls the permeability change of the bed, and the latter porosity change controls the diffusion of $\mathrm{OH}^{-}$ions inducing the dissolution of silica.

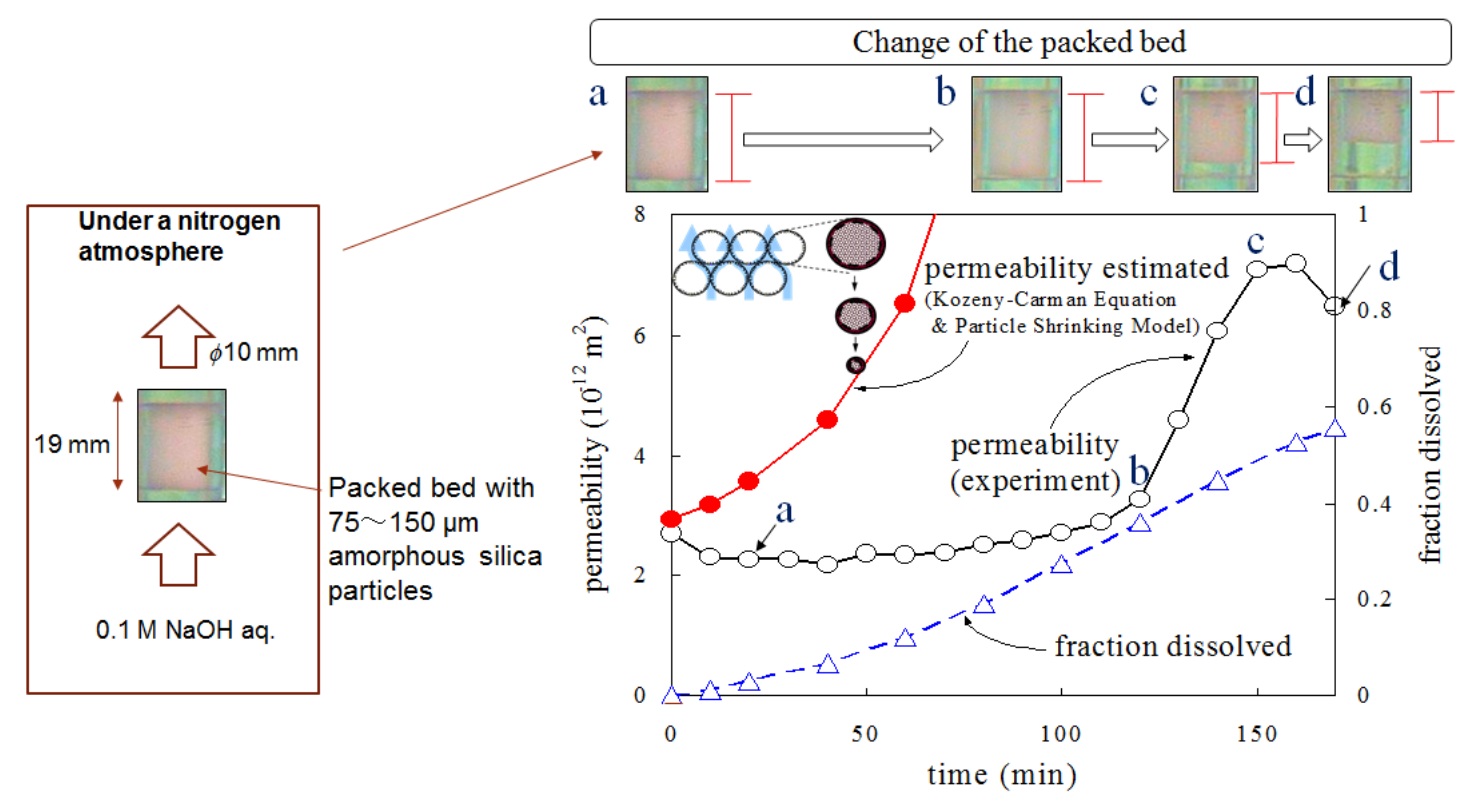

Fig. 1 Experimental result of permeability change due to the continusous injection of $\mathrm{NaOH} 0.1 \mathrm{M}$ soltion to the bed packed with amorphous silica partilces (Usui et al., 2004). (In this figure, “a”, “b”, “c” and “d” are the photographs indicating the states of the packed bed in the experiment. Note that the height of the packed bed was held at least until the state of "a" of the packed bed attained to the state of "c".)

\section{Mathematical model}

The $\mathrm{SiO}_{2}$ dissolution reaction is given by

$$
\mathrm{SiO}_{2}+\mathrm{NaOH}+\mathrm{H}_{2} \mathrm{O} \rightarrow \mathrm{H}_{3} \mathrm{SiO}_{4}^{-}+\mathrm{Na}^{+} .
$$

This reaction is the following type;

$$
\mathrm{A}(\mathrm{s})+\mathrm{B}(\mathrm{aq}) \rightarrow \mathrm{C}(\mathrm{aq})
$$

In the range of $\mathrm{pH} 13, \mathrm{H}_{3} \mathrm{SiO}_{4}^{-}$is a dominant chemical species. $\mathrm{SiO}_{2}$ dissolution reaction rate is equal to the consumption rate of $\mathrm{OH}^{-}$ions, $r_{\mathrm{B}}$, described by the following first-order reaction equation,

$$
-r_{\mathrm{B}}=k C_{\mathrm{B}} \text {, }
$$

where $k$ is rate constant, $C$ is the concentration, and the subscript $\mathrm{B}$ means $\mathrm{OH}^{-}$ions.

Figure 2 shows an illustration of the mathematical model. The column is the packed bed of the particle clusters. The initial radius of particles is $r_{0}$. The initial diameter of the particle cluster is $R_{0}(\mathrm{~m})$. With dissolution reaction, the 
outer small particles of the particle cluster shrink with a decrease in radius, and the porosity of the outer particle layer, $\varepsilon$, increases. Then, the diffusion rate of $\mathrm{OH}^{-}$ions also increases. That is, the diffusion rate in the outer layer exceeds that in the inner region. Therefore, the dissolution rate in the outer layer becomes larger than the rate in the inner region. Furthermore, the diameter of particle cluster, $R(\mathrm{~m})$, decreases (shrinks), when the radius of the particles, $r$, reaches zero. The dissolution amount at an arbitrary time in the packed bed is equal to the total dissolution amount of particles. Besides, the permeability is described using the porosity of the packed bed of the particle clusters, $\varepsilon_{\mathrm{L}}$, by the Kozeny-Carman equation.

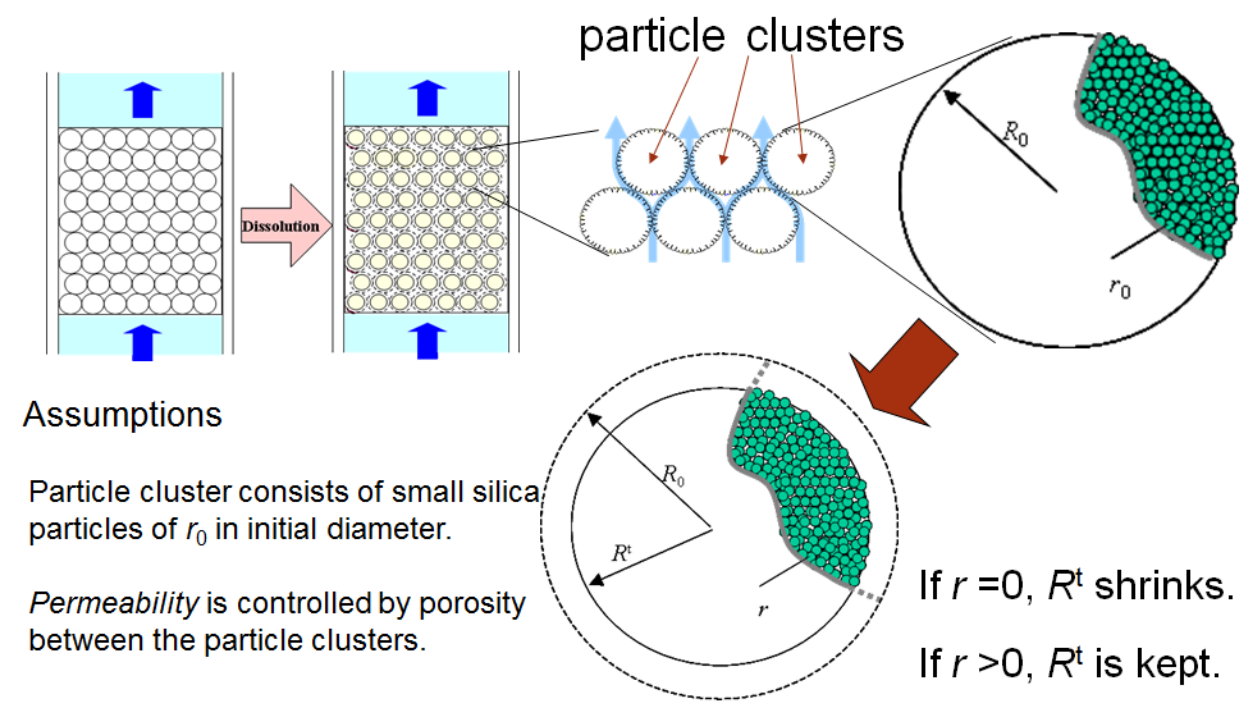

Fig. 2 Illustration of the proposed model.

Additionally, it is assumed that

(a) In the flow system, a $0.1 \mathrm{M} \mathrm{NaOH}$ solution is continuously injected into column, and its concentration is maintained up to the outlet of column. (Its validity was confirmed by the experimental data reported by Usui et al. 2004).

(b) The particles (initial diameter $r_{0}$ ) are sufficiently small compared to the particle clusters (initial diameter $R_{0}$ ),

(c) The packed bed is under an isothermal condition,

(d) The number densities of the particles and the particle clusters, $n_{0}$ and $n_{\mathrm{L} 0}$, are not changed,

(e) Each position of the particles and the particle clusters is immobile, until the radius reaches zero,

(f) The effective diffusion coefficient, $D_{\mathrm{Be}}$, in the particle cluster is described by $D_{\mathrm{Be}}=\varepsilon^{2} D_{\mathrm{B}}$ (Wakao and Smith, 1969), where $\varepsilon$ is the porosity of the cluster, and $D_{\mathrm{B}}$ is the diffusion coefficient of $\mathrm{OH}^{-}$ions in a solution,

(g) The mass transfer coefficient of $\mathrm{OH}^{-}$ions from the flowing solution to the particle cluster is described by Ranz-Marchall equation.

The assumption (g) includes the change of the mass transfer coefficient with the shrinking of the particle clusters due to the dissolution reaction. The Ranz-Marchall equation is

$$
S h=2.0+0.6(R e)^{1 / 2}(S c)^{1 / 3},
$$

where $S h$ is Sherwood number $\left(=k_{\mathrm{f}}\left(2 R^{\mathrm{t}}\right) / D_{\mathrm{B}}\right)$, Re is Reynolds number $\left(=\left(2 R^{\mathrm{t}}\right) u \rho / \mu\right)$, and $S c$ is Schmidt number $\left(=\mu /\left(\rho D_{\mathrm{B}}\right)\right)$. In these dimensionless parameters, $k_{\mathrm{f}}$ is the mass transfer coefficient, $R^{\mathrm{t}}$ is the diameter of the particle cluster at time $t, u$ is the fluid flow velocity between the particle clusters, $\mu$ and $\rho$ are the viscosity and the density of the flowing solution, respectively.

Figure 3 shows the SEM images of the surface of silica particle, which is called "particle cluster" in this model. Here, $f$ is the fraction dissolved, the definition of which is given by Eq. (14) below. It can be seen that the particle cluster consisted of small particles. (Note the window indicated by square in Fig. 3 (a).) As shown in Fig. 3(b), with silica dissolution, the surface seems to further become porous, while leaving some frames. That is, the dissolution reaction increases the porosity, $\varepsilon$, which introduces $\mathrm{OH}^{-}$ions more easily into the inside of the particle cluster. Then, 
$\mathrm{OH}^{-}$ions can diffuse more easily into the inside of the particle cluster. Furthermore, as shown in Fig. 1, some frames left in the surface holds the height of the packed bed at least until the state of "a" of the packed bed attains to the state of "c". This observed behavior became a base of both the assumptions (d) and (e) mentioned above. In the addition of these assumptions, this model tries to describe these dissolution processes, by assuming a rule, "If $r=0, R_{\mathrm{t}}$ shrinks, If $r>0, R_{\mathrm{t}}$ is kept", as indicated in Fig. 2.

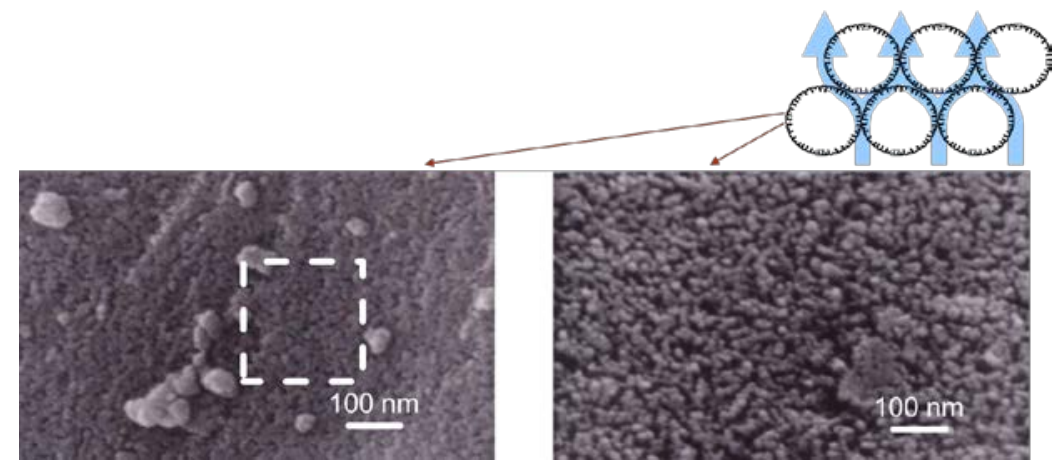

(a) $f=0.0$

(b) $f=0.15$

Fig. 3 SEM images of the surface of amorphous silica particle (Usui et al., 2004). ( $f$ : fraction dissolved)

The fundamental equation yields

$$
\frac{1}{R^{2}} \frac{\partial}{\partial R} R^{2} D_{B e} \frac{\partial C_{B}}{\partial R}-k 4 \pi r^{2} n_{0} C_{B} \varepsilon=\frac{\partial \varepsilon C_{B}}{\partial t},
$$

where $R$ is the radius of the particle cluster, $C_{\mathrm{B}}$ is the concentration of $\mathrm{OH}^{-}$ions in the particle cluster, $r$ is the radius of the particle, $n_{0}$ is number per unit volume of particle cluster, and $t$ is time. The first term in the left-hand side of Eq. (5) means the diffusion of $\mathrm{OH}$ ions in the particle cluster, and the second term means the $\mathrm{OH}$ ions consumption caused by the dissolution of the particles in the particle clusters. Here, the radius of the particle, $r$, is not uniform, as described by Eq. (11) below. Furthermore, when $r=0$, the second-term on the left-hand side of the Eq. (5) becomes 0 . That is, the total number of the particles decreases in a particle cluster. Chida and Tadaki (1979) have proposed a similar model, assuming that $\varepsilon$ is constant in Eq. (5). However, we cannot neglect the change of $\varepsilon$ which is a key variable for describing the present problem.

The boundary conditions are

$$
\begin{gathered}
\frac{\partial C_{B}}{\partial R}=0, \quad \text { at } R=0, \\
D_{B e} \frac{\partial C_{B}}{\partial R}=k_{f}\left(C_{B b}-C_{B}\right), \quad \text { at } R=R^{t},
\end{gathered}
$$

where $C_{\mathrm{Bb}}$ is the bulk concentration of $\mathrm{OH}^{-}$ions between the particle clusters. In the flow system, a $0.1 \mathrm{M} \mathrm{NaOH}$ solution was continuously injected into the column. $C_{\mathrm{Bb}}$ is assumed to be constant in this model.

The initial conditions are

$$
C_{\mathrm{B}}=0, \quad R^{\mathrm{t}}=R_{0}, \quad r=r_{0}, \quad \varepsilon=\varepsilon_{0} \quad \text { in } \quad 0 \leq R \leq R_{0},
$$

where the subscript 0 means each initial value.

Since the porosity $\varepsilon$ can be given by the following equation based on the assumptions (d) and (e),

$$
\left(1-\varepsilon_{0}\right) /(1-\varepsilon)=\frac{4}{3} \pi r_{0}^{3} n_{0} / \frac{4}{3} \pi r^{3} n_{0}
$$

we can obtain

$$
\varepsilon=1-\left(1-\varepsilon_{0}\right)\left(\frac{r}{r_{0}}\right)^{3},
$$

Furthermore, the change of $r$ (the radius of small particle) with time yields 


$$
-\frac{d r}{d t}=k C_{B} \frac{S}{\rho_{S}}
$$

where $S$ is a stoichiometric coefficient described by (the stoichiometric coefficient of dissolution reaction) $\times$ (conversion factor between density and moles), and $\rho_{\mathrm{S}}$ is the density of solid phase.

Now consider $R^{\mathrm{t}}$ as follows:

$$
R^{t}=R_{r=0} .
$$

That is, as the radius of the particle becomes zero in the most outer layer of the particle cluster, the particle cluster shrinks. Besides, since the dissolved fraction of the particle, $f_{\mathrm{s}}$, is described by

$$
f_{s}=\frac{\frac{4}{3} \pi r_{0}^{3}-\frac{4}{3} \pi r^{3}}{\frac{4}{3} \pi r_{0}^{3}}=1-\frac{r^{3}}{r_{0}^{3}},
$$

the fraction dissolved of the whole bed packed with particle clusters, $f$, is

$$
f=\frac{\frac{4}{3} \pi R_{0}^{3}-\frac{4}{3} \pi\left(R^{t}\right)^{3}}{\frac{4}{3} \pi R_{0}^{3}}+\frac{\int_{0}^{R^{t}} f_{s} 4 \pi R^{2} d R}{\frac{4}{3} \pi R_{0}^{3}}=1-\left(\frac{R^{t}}{R_{0}}\right)^{3}+3 \int_{0}^{R^{t}} f_{s} \frac{R^{2}}{R_{0}^{3}} d R .
$$

The first-term on the right hand side of Eq. (14) means the fraction dissolved of the particles in the range from $R_{0}$ to $R^{\mathrm{t}}$ in particle cluster radius. In this range, the particles do not exist, due to dissolution. The second-term indicates the dissolved fraction of particles in $0<R<R^{t}(R$ : the radius from the center in particle cluster). Here, small particles still remain with $r>0$.

Next, describe the permeability of the packed bed. The porosity of the particle clusters, $\varepsilon_{\mathrm{L}}$, yields the following relation:

$$
\left(1-\varepsilon_{L 0}\right) /\left(1-\varepsilon_{L}\right)=\frac{4}{3} \pi R_{0}^{3} n_{L 0} / \frac{4}{3} \pi\left(R^{t}\right)^{3} n_{L 0},
$$

where $\varepsilon_{\mathrm{L} 0}$ is the initial porosity between particle clusters, and $n_{\mathrm{L} 0}$ is the number of particle clusters in unit volume.

Therefore, $\varepsilon_{\mathrm{L}}$ is

$$
\varepsilon_{L}=1-\left(1-\varepsilon_{L 0}\right)\left(\frac{R^{t}}{R_{0}}\right)^{3} .
$$

Assuming that the permeability is not controlled by $\varepsilon$ but just by $\varepsilon_{\mathrm{L}}$, the Kozeny-Carman equation gives permeability normalized by the initial permeability in the packed bed:

$$
K_{\text {Bed }}=\left(\frac{a_{0}}{a}\right)^{2} \frac{\varepsilon_{L}^{3}}{\left(1-\varepsilon_{L}\right)^{2}} \frac{\left(1-\varepsilon_{L 0}\right)^{2}}{\varepsilon_{L 0}{ }^{3}}, \quad a_{0}=\frac{3}{R_{0}}, a=\frac{3}{R^{t}},
$$

where $a$ is the specific surface area of the particle cluster.

The initial radius of the particle cluster, $R_{0}$, is around $50 \mu \mathrm{m}$, and, as shown in Fig. 3, each particle cluster consists of a number of particles of $10 \mathrm{~nm}$ in initial radius. The number of the particles per unit volume of the particle cluster, $n_{0}$, is approximately $10^{17}$. Since the second-term of the left hand side of Eq. (5) remarkably exceeds the first term, the diffusion of $\mathrm{OH}^{-}$ions controls the dissolution processes, which in turn gives an induced time before changing the permeability, $K_{\text {Bed. }}$

In order to sort out the parameters of this model, this study used the dimensionless variables defined as follows:

$$
\begin{aligned}
& X=\frac{R}{R_{0}}, \quad Z=\frac{r}{r_{0}}, Y=\frac{C_{B}}{C_{B_{b}}}, E=\frac{\varepsilon}{\varepsilon_{0}}, D_{e}=\frac{D_{B e}}{D_{B e 0}}=\left(\frac{\varepsilon}{\varepsilon_{0}}\right)^{2}, P_{v}=\frac{R_{0} 4 \pi r_{0} k n_{0} \varepsilon_{0}}{D_{B e 0}}, D_{B e 0}=\varepsilon_{0}^{2} D_{B}, P_{t}=\frac{R_{0}^{2} \varepsilon_{0}}{t^{*} D_{B e 0}}, \\
& T=\frac{t}{t^{*}}, t^{*}=\frac{\rho_{s} r_{0}}{k C_{B b} S}, \quad S h^{\prime}=\frac{k_{f}\left(2 R^{t}\right)}{D_{B e 0}}, X^{t}=\frac{R^{t}}{R}, \quad S h=\frac{k_{f}\left(2 R^{t}\right)}{D_{B_{b}}}, \quad R e=\frac{\rho u\left(2 R^{t}\right)}{\mu}, \quad S c=\frac{\mu}{\rho D_{B_{b}}} .
\end{aligned}
$$

Using these variables, the fundamental Eqs. (5) and (11) are 


$$
\begin{gathered}
\frac{1}{X^{2}} \frac{\partial}{\partial X}\left(X^{2} D_{e} \frac{\partial Y}{\partial X}\right)-P_{v} Z^{2} Y E=P_{t} \frac{\partial(E Y)}{\partial T}, \\
-\frac{d Z}{d T}=Y,
\end{gathered}
$$

and the boundary conditions (6) and (7) are

$$
\begin{aligned}
& \frac{\partial Y}{\partial X}=0, \quad \text { at } \quad X=0, \\
& D_{e} \frac{d Y}{d X}=\frac{S_{h}{ }^{\prime}}{2 X^{t}}(1-Y), \quad \text { at } X=X^{t} .
\end{aligned}
$$

The initial conditions are

$$
Y=0, \quad Z=1, \quad X^{t}=1, \quad E=1, \quad \text { at } T=0 \text {, in } 0 \leq X \leq 1 .
$$

Besides, the relations mentioned above are

$$
\begin{gathered}
S h=2.0+0.6(R e)^{1 / 2}(S c)^{1 / 3}, \quad S h^{\prime}=S h \frac{D_{B b}}{D_{B e 0}}, \\
\frac{R e^{t}}{R e_{0}}=\frac{R^{t}}{R_{0}} \frac{\varepsilon_{L 0}}{\varepsilon_{L}^{t}}, \quad\left(R e=\frac{2 R^{t} \rho\left(u_{D} / \varepsilon_{L}\right)}{\mu}, \quad R e_{0}=\frac{2 R_{0} \rho\left(u_{D} / \varepsilon_{L 0}\right)}{\mu}\right), \\
f=1-\left(X^{t}\right)^{3}+3 \int_{0}^{X^{t}} f_{X} X^{2} d X, \quad f_{X}=1-Z^{3},
\end{gathered}
$$

and,

$$
E=\frac{1-\left(1-\varepsilon_{0}\right) Z^{3}}{\varepsilon_{0}}
$$

in each dimensionless form. (Note that the Reynolds number also changes with time through the change of the radius of the particle cluster, $R^{\mathrm{t}}$.)

Furthermore, in pseudo steady state Eq. (18) becomes

$$
\frac{1}{X^{2}} \frac{\partial}{\partial X}\left(X^{2} D_{e} \frac{\partial Y}{\partial X}\right)-P_{v} Z^{2} Y E=0
$$

where the change of dimensionless porosity with time, $E$, is described by Eqs. (19) and (25). The validity of this assumption will be discussed later. Besides, in Eq. (23), there are two kinds of Sherwood number. Assuming $D_{\mathrm{Be} 0}=\varepsilon_{0}^{2} D_{\mathrm{B}}$, the relation is

$$
S h^{\prime}=S h / \varepsilon_{0}^{2} .
$$

These five values can be calculated by using the data set in Table 1 , where the fluid flow velocity, $u$, was estimated from Darcy fluid flow velocity $u_{\mathrm{d}}$ through $u=u_{\mathrm{d}} / \varepsilon_{\mathrm{L}}$. Of these five parameters, $(R e)_{\mathrm{T}=0}$ and $S c$ are used in order to calculate $\left(S h^{\prime}\right)_{\mathrm{T}=0}$ through the Ranz-Marchall equation (i.e., Eq.(4)). Therefore, the three parameters, $P_{\mathrm{v}}, t^{*}$ and $\left(S h^{\prime}\right)_{\mathrm{T}=0 \text {, }}$ control this model.

As for the dissolution rate constants as shown in Table 1, this study has to mention the reason why there are two kinds of rate constants. Niibori et al. (2000) have applied the particle shrinking model to the dissolution batch experiment of amorphous silica particles in order to estimate the dissolution rate constant. As the results, they reported that there was an induced time in the range of $0<1-(1-f)^{1 / 3}<0.1$ (which means the range from 0 to 0.27 in fraction dissolved) before the shrinking model described the dissolution behavior. Then, they estimated $8.98 \times 10^{-10} \mathrm{~m} / \mathrm{s}$ as dissolution rate constant after the induced time. Therefore, in $0 \leq f \leq 0.27$, this study evaluated $4.49 \times 10^{-10} \mathrm{~m} / \mathrm{s}$ by using the experimental data as an apparent rate constant in the induced time, while such a rate constant might be continuously changing around at 0.27 in $f$.

Besides, in Table 1, the number of small particles per unit particle cluster volume, $n_{0}\left(1 / \mathrm{m}^{3}\right)$, was calculated by

$$
n_{0}=\frac{1-\varepsilon_{0}}{\frac{4}{3} \pi r_{0}^{3}},
$$


where $\varepsilon_{0}$ is the porosity in a particle cluster, and $\mathrm{r}_{0}$ is the initial radius of particle.

This study used the finite volume method in order to numerically solve the mathematical model, setting 100 uniform meshes as control volumes. It was confirmed by prior calculations that the number of meshes was enough to obtain a unique numerical solution.

Table 1 The data set of the parameters.

\begin{tabular}{|c|c|c|c|}
\hline & Symbol & Value & Remarks \\
\hline$C_{\mathrm{B} 0}$ & Concentration of $\mathrm{NaOH}$ in continuously injected solution & $0.10 \mathrm{M}$ & Experimental condition (Usui et al., 2004) \\
\hline$D_{\mathrm{Bb}}$ & Diffusion coeffcient of $\mathrm{OH}^{-}$in bulk (liquid phase) & $5.30 \times 10^{-9} \mathrm{~m}^{2} / \mathrm{s}$ & Atkins and Paula (1998) \\
\hline$k$ & Dissolution rate constant & $\begin{array}{l}4.49 \times 10^{-10} \mathrm{~m} / \mathrm{s} \text { in } \\
0 \leq f<0.27 \\
8.98 \times 10^{-10} \mathrm{~m} / \mathrm{s} \text { in } \\
0.27 \leq f \leq 1.0\end{array}$ & $\begin{array}{l}\text { Experomentally evaluated value (Niibori et al., 2000). } f \\
\text { means fraction dissolved. }\end{array}$ \\
\hline$n_{0}$ & $\begin{array}{l}\text { Number of small silica particles per unit volume of } \\
\text { particle cluster }\end{array}$ & $1.67 \times 10^{23} / \mathrm{m}^{3}$ & Estimated value by using porosity $\varepsilon_{0}$ and Eq. (28). \\
\hline$R_{0}$ & Initial radius of particle cluster & $5.60 \times 10^{-5} \mathrm{~m}$ & $\begin{array}{l}\text { Experimental condition (Usui et al., 2004): the average } \\
\text { radius in a size fraction of } 74 \mu \mathrm{m} \text { to } 149 \mu \mathrm{m} \text {. }\end{array}$ \\
\hline$r_{0}$ & Initial radius of small silica particle & $1.00 \times 10^{-8} \mathrm{~m}$ & SEM image (diameter: $20 \mathrm{~nm}$ ) (Usui et al., 2004) \\
\hline$S$ & $\begin{array}{l}\text { (stoichiometric coefficient of dissolution reaction) } \times \\
\text { (conversion factor between density and moles) }\end{array}$ & $6.68 \times 10^{-2} \mathrm{~kg} / \mathrm{mol}$ & $\begin{array}{l}\text { Dissolusion reaction: Eq. (1) } \\
\text { Solid sample: } \mathrm{SiO}_{2} \cdot 038 \mathrm{H}_{2} \mathrm{O} \text { (Niibori et al. , 2000) }\end{array}$ \\
\hline$u$ & Fluid flow velocity in pores between particle clusters & $8.25 \times 10^{-4} \mathrm{~m} / \mathrm{s}$ to & Experimental condition (Usui et al., 2004) \\
\hline$\varepsilon_{0}$ & $\begin{array}{l}\text { Initial porosity between the small silica particles in the } \\
\text { particle cluster }\end{array}$ & 0.30 & Experomental measuement value (Niibori et al., 2004) \\
\hline$\varepsilon_{\mathrm{L} 0}$ & $\begin{array}{l}\text { Initial porosity between the particle clusters in packed } \\
\text { bed }\end{array}$ & 0.40 & Experimental measurement value (Usui et. al., 2004) \\
\hline$\mu$ & Viscosity of continuously injected solution & $1.00 \times 10^{-3} \mathrm{~Pa} \cdot \mathrm{s}$ & $\begin{array}{l}\text { Experimental condition (temperature: } 296 \text { K, Usui et al., } \\
\text { 2004) }\end{array}$ \\
\hline$\rho$ & Density of continuously injected solution & $100 \times 10^{3} \mathrm{~kg} / \mathrm{m}^{3}$ & $\begin{array}{l}\text { Experimental condition (temperature: } 296 \mathrm{~K} \text {, Usui et al., } \\
2004 \text { ) }\end{array}$ \\
\hline$\rho_{\mathrm{S}}$ & Density of small silica particles (not the particle clusters) & $2.00 \times 10^{3} \mathrm{~kg} / \mathrm{m}^{3}$ & Experomental measuement value (Niibori et al., 2000) \\
\hline
\end{tabular}

\section{Result and discussion}

Figure 4 shows the results of the normalized permeability in comparison of the mathematical model with the experimental data reported by Usui et al. (2004). In the experiment, the packed bed was vertically set, and a $0.1 \mathrm{M}$ $\mathrm{NaOH}$ solution continuously flowed downward from the top to the bottom. As for the fraction dissolved, $f$, there is an inflection point at 0.27 in $f$. This is due to the change of $P_{\mathrm{v}}$ containing the dissolution rate constant. The mathematical model can describe the experimental data both of permeability and fraction dissolved well. However, when the dimensionless time exceeded 2.5, the permeability data suddenly decreased. This is due to the shifts of the positions of the particle clusters in the packed bed. That is, the particle clusters, gradually shrinking, each other become shiftable in the column. This model cannot essentially describe such a behavior in permeability.

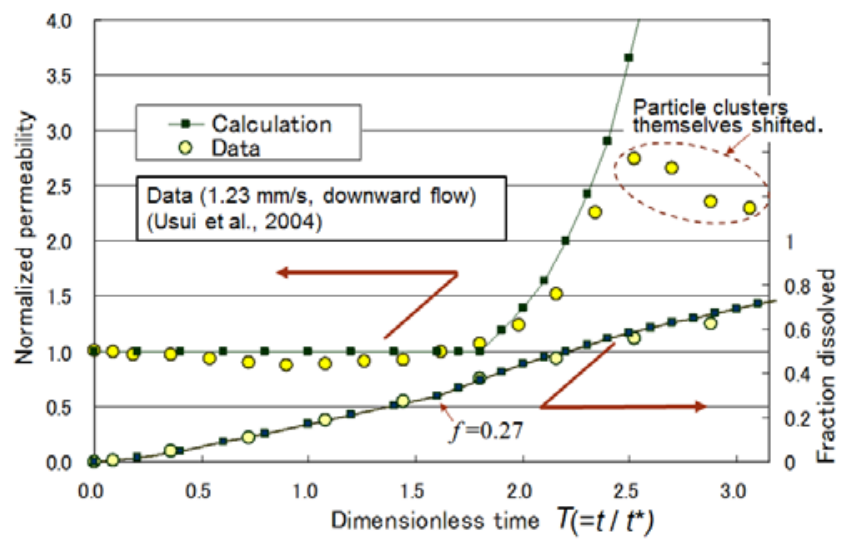

Fig.4 Comparison of the mathematical model with the experimental data. (Model Parameters: $P_{\mathrm{v}}=0.19$ (in 0. $\leq f<027$ ), 0.37 (in $0.27 \leq f \leq 1.0), t^{*}=3,333 \mathrm{~s},\left(S h^{\prime}\right)_{\mathrm{T}=0}=44.7,(R e)_{\mathrm{T}=0}=0.34$, and $S c=1.89 \times 10^{2}$.) 
Figure 5 shows the relations between permeability and $f$ (fraction dissolved), where the experimental data of 0.33 $\mathrm{mm} / \mathrm{s}$ in lateral flow and those of $1.35 \mathrm{~mm} / \mathrm{s}$ in upward flow are added to those of downward flow in Fig. 4. The fluid flow velocity has no appreciable effect on the relation between normalized permeability and $f$. While the mathematical model does not consider flow direction of the column, the calculated result agree well with the experimental data. Particularly, this model can predict the permeability changes until around 0.6 in fraction dissolved $f$.

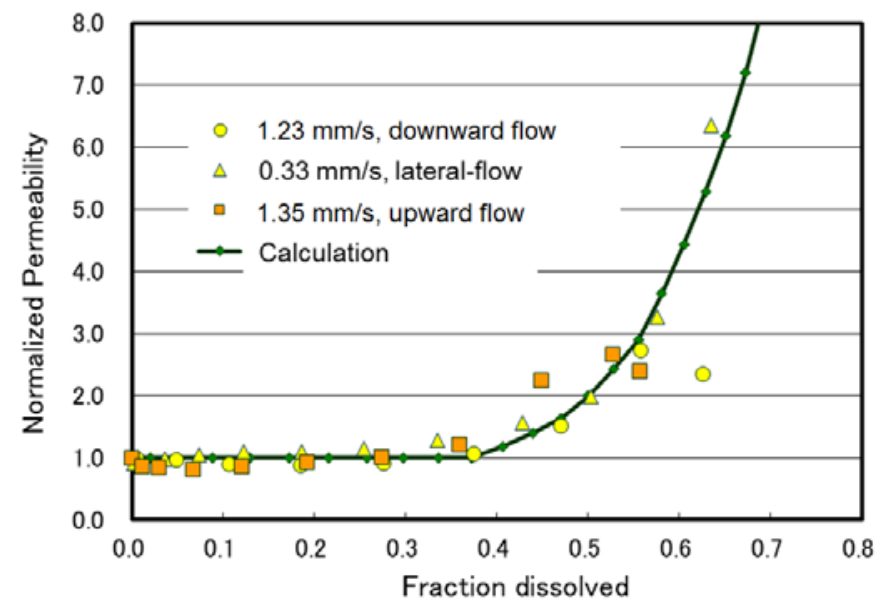

Fig. 5 Relations between permeability and $f$ (fraction dissolved).

(These experimental data were quoted from Usui et al. (2004).)

Figure 6 shows the distribution of the radius of the particles $(Z)$ and the concentration of $\mathrm{NaOH}(Y)$ inside the particle cluster. $T=1.8$ is the timing that the radius of the particles becomes zero at $X=1.0$ in radius of the particle cluster. After that, the permeability of the packed bed with the particle clusters increases. Besides, the $\mathrm{NaOH}$ concentration becomes 0.0 at $X=0.7$, while the concentration is 1.0 at $X=1.0$. Furthermore, with time, the position of $Z=0$ shifts toward the center $(X=0)$ of the particle cluster. The position of $Y=0$ as well shifts toward the center.

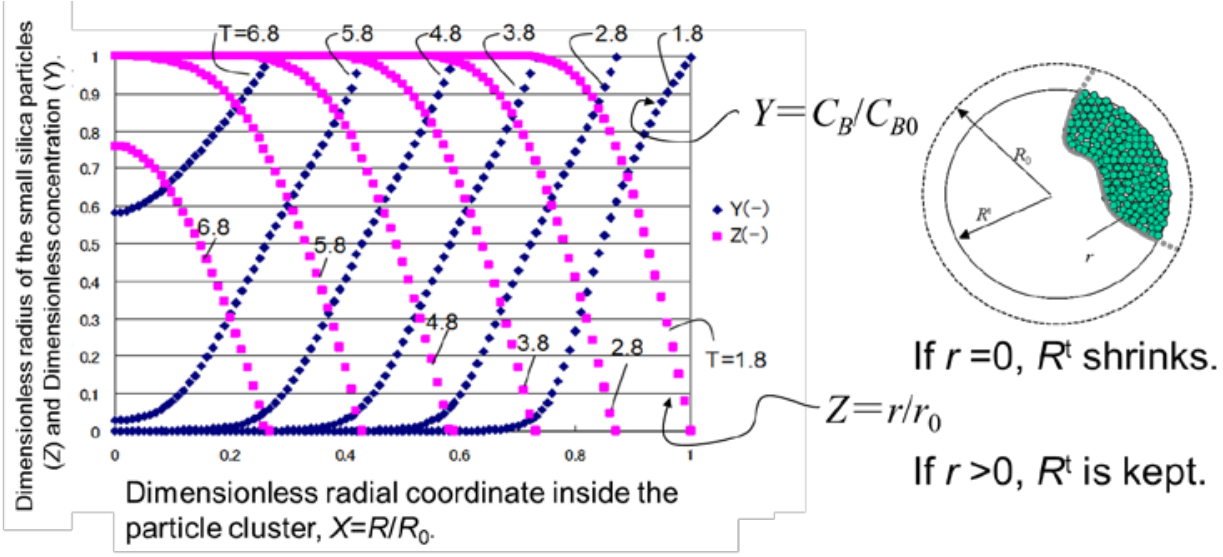

Fig. 6 Distributions of calculated radius of particles and the concentration of $\mathrm{NaOH}$, in relation to radius in particle cluster. ( $T$ is time in dimensionless form).

Figure 7 shows the calculated results of porosity and the radius of the particles $(Z)$ in the particle cluster. This model describes that the porosity attains to 1.0 at $X=1$ and at $T=1.8$, and the particle cluster starts shrinking. Then, the location of $\varepsilon=1.0$ is gradually shifting toward the center of the particle cluster. This means the decrease of $R^{\mathrm{t}}$ with time. Besides, this model explains that $\mathrm{OH}^{-}$ions diffuse until around one third of the initial size of the particle cluster when $T=2.8$ ( $t=155$ mins). That is, both the dissolution of silica and the permeability-change of whole column are controlled mainly by the diffusion of $\mathrm{OH}^{-}$ions through the particle clusters. 


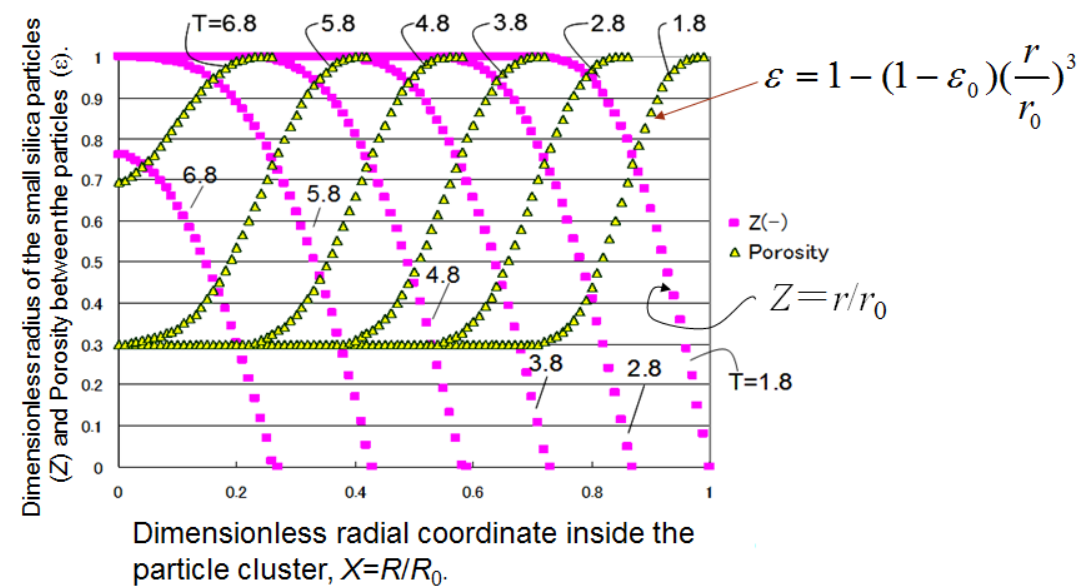

Fig. 7 Distributions of calculated porosity and radius of particles inside particle cluster.

These approaches of this study may be applicable to describe the relation between the dissolution processes on the fracture surface and the permeability change of fracture. Because, the fracture surface included in rock matrix consists of various minerals whose dissolution rates also are not uniform on the surfaces, for example: (Usui et al., 2005). In general, such a permeability $\left(\mathrm{m}^{2}\right)$ is approximately described by $b^{2} / 12$ in Darcy-type equation, where $b$ is fracture aperture (m). The permeability of fracture is not always sensitive against the dissolution processes. That is, as shown in Fig. 8, the proposed model in this study suggests that the characteristic aperture $b$ does not change immediately, while the dissolution process undergoes in a time period.

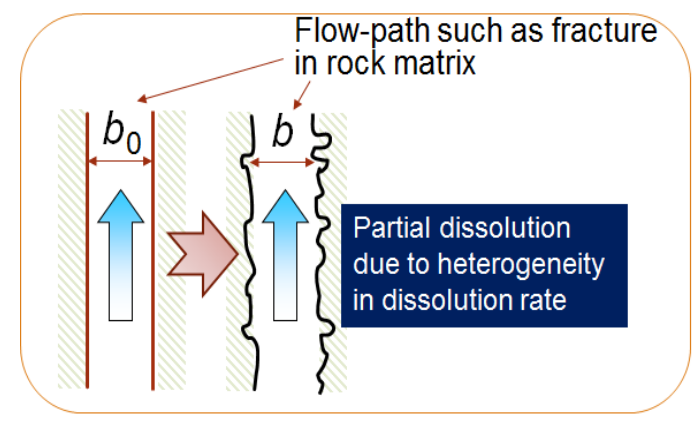

Fig. 8 Illustration of fracture surface with dissolution processes.

\section{Conclusions}

This study proposed a double porosity model to describe the dynamic behaviors of both the fraction dissolved and the permeability of the packed bed of silica particle cluster, by assuming two kinds of porosities between particle clusters and between the particles. In the column experiment using a $0.1 \mathrm{M} \mathrm{NaOH}$ solution, the permeability was maintained in a certain time period, while $\mathrm{Si}$ (mainly as $\mathrm{H}_{3} \mathrm{SiO}_{4}^{-}$ions) was continuously eluted out of the packed bed with silica particles. The proposed model was able to well explain such dynamic behaviors.

When we consider a high $\mathrm{pH}$ groundwater plume resulting from the alteration of cement materials for constructing the repository system of radioactive wastes, this model might be a practical tool to describe both permeability-change and dissolution process, particularly under a condition such that the mass transport of solute apparently controls the chemical reaction in a flow field.

\section{Nomenclature}

$a \quad$ Specific surface area of particle cluster $\left(=3 / R^{t}\right)(1 / \mathrm{m})$

$b \quad$ Fracture aperture (m) 


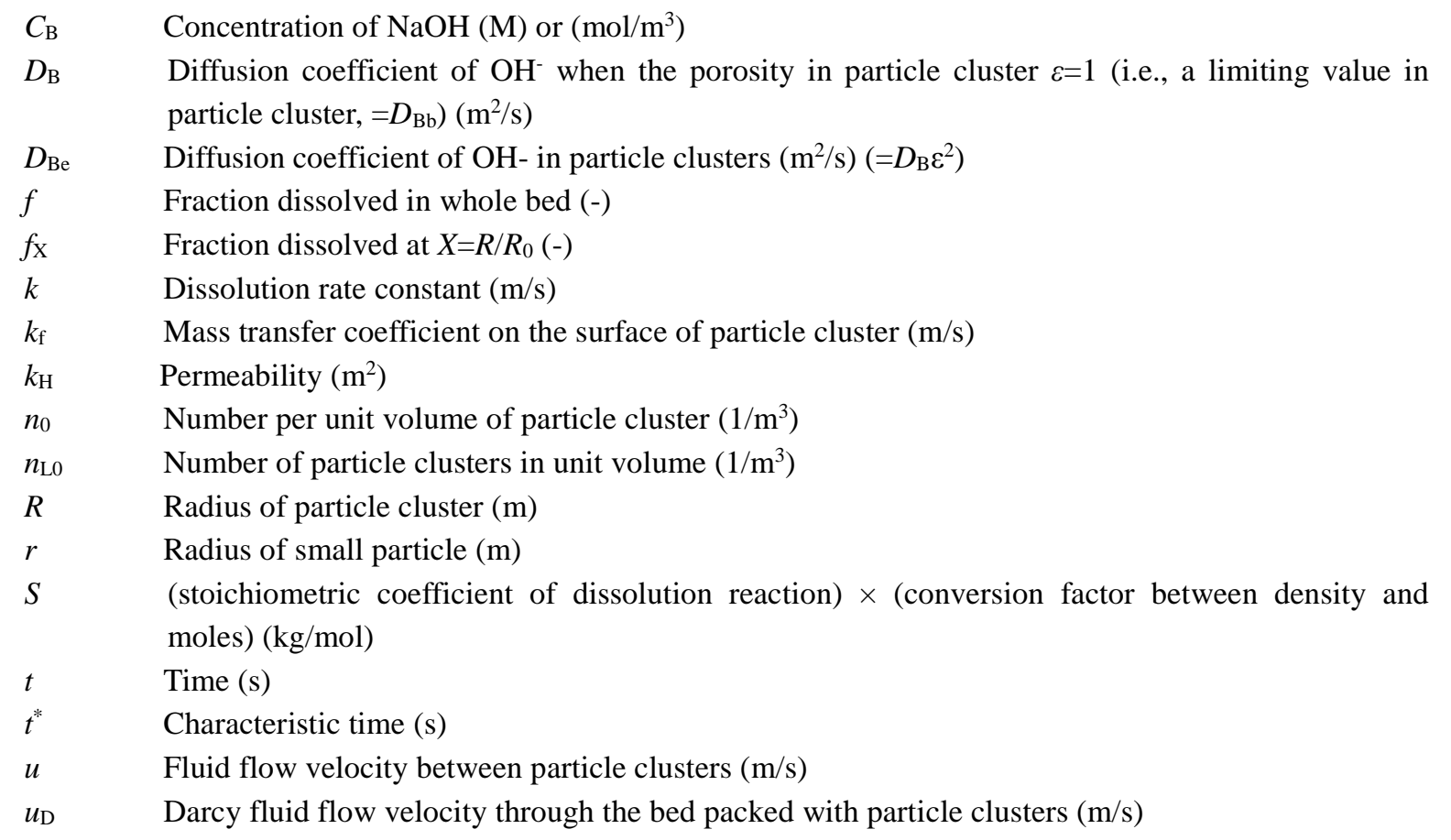

\section{Greek symbols}

$\varepsilon \quad$ Porosity between the small silica particles in the particle cluster (-)

$\varepsilon_{\mathrm{L}} \quad$ Porosity between the particle clusters in packed bed (-)

$\rho \quad$ Density of feed solution $\left(\mathrm{kg} / \mathrm{m}^{3}\right)$

$\rho_{\mathrm{S}} \quad$ Density of small silica particles (not the particle clusters) $\left(\mathrm{kg} / \mathrm{m}^{3}\right)$

$\mu \quad$ Viscosity of feed solution (Pa·s)

\section{Dimensionless numbers}

$D_{\mathrm{e}} \quad$ Dimensionless diffusion coefficient in particle cluster $\left(=D_{\mathrm{Be}} / D_{\mathrm{Be} 0}\right)$

$K_{\text {Bed }} \quad$ Permeability of packed bed (Note Eq. (17))

$P_{\mathrm{v}} \quad$ Dimensionless parameter $\left(=4 \pi r_{0}^{2} k n_{0} R_{0}^{2} \varepsilon_{0} / D_{\mathrm{Be} 0}\right)$

$P_{\mathrm{t}} \quad$ Dimensionless parameter $\left(=R_{0}^{2} \varepsilon_{0} /\left(t^{*} D_{\mathrm{Be} 0}\right)\right)$

Re Reynolds number $\left(=2 R^{\mathrm{t}} \rho u / \mu\right)$

Sc $\quad$ Schmidt number $\left(=\mu /\left(\rho D_{\mathrm{Bb}}\right)\right)$

Sh Sherwood number $\left(=2 R^{\mathrm{t}} k_{\mathrm{f}} / D_{\mathrm{Bb}}\right)$

$S h^{\prime} \quad$ Sherwood number $\left(=2 R^{\mathrm{t}} k_{\mathrm{f}} / D_{\mathrm{Be}}\right)$

$T \quad$ Dimensionless time $\left(=t / t^{*}, t^{*}=\rho_{\mathrm{s}} r_{0} /\left(k C_{\mathrm{Bb}} S\right)\right)$

$X \quad$ Dimensionless radius of particle cluster $\left(=R / R_{0}\right)$

$Y \quad$ Dimensionless concentration $\left(=C_{\mathrm{B}} / C_{\mathrm{Bb}}\right)$

$Z \quad$ Dimensionless radius of particle $\left(=r / r_{0}\right)$

$E \quad$ Dimensionless porosity in particle cluster $\left(=\varepsilon / \varepsilon_{0}\right)$

\section{Subscript}

$0 \quad$ Initial value

b Value in bulk

L Cluster

\section{Superscript}

$\mathrm{t} \quad$ Value at time $\mathrm{t}$

\section{Acknowledgments}

The authors are grateful to Prof. J. Ahn, Department of Nuclear Engineering, University of California, Berkeley, 
for his valuable comments. This study was supported by Japan Society for the Promotion of Science, Grant-in-Aid for Challenging Exploratory Research, No. 25630425.

\section{References}

Atkins, P., and Paula, J. D., Physical Chemistry, (6th ed.), p.984 (1998).

Atkinson, A., The Time Dependence of pH within a Repository for Radioactive Waste Disposal, AERE R 11777, UKAEA (1985).

Chida, T., and Tadaki, T., Mathematical Analysis of Kinetic of Solid-consuming Reaction, Journal of Chemical Engineering of Japan, Vol.12, No.3 (1979), pp.220-224.

FEPC (Federation of Electric Power Companies of Japan) and JNC (Japan Nuclear Cycle development institute), “Second TRU progress report”, JNC TY1400 2005-013, FEPC TRU-TR2-2005-02 (2005).

Funabashi, T., Niibori, Y. and Mimura, H., Sorption behavior of Eu(III) into CSH gel in imitated saline groundwater, Proceedings of WM2012 Conference (February 26 - March 1, 2012, Phoenix, AZ), Paper No. 12145 (2012) pp. $1-11$.

Iler, R. K., The Chemistry of Silica: Solubility, polymerization, Colloidal and Surface Properties, and Biochemistry, John Wiley \& Sons (1979).

JNC (Japan Nuclear Cycle development institute), H12 Project to Establish the Scientific and Technical Basis for HLW Disposal in Japan, Supporting Report I, Geological Environment in Japan, Chapters V \& VI (1999).

Mäder, U. K., Fierzb, T., Friegc, B., Eikenbergd, J., Rüthid, M., Albinssone, Y., Mörif, A., Ekberge, S., and Stille, P., Interaction of hyperalkaline fluid with fractured rock: Field and laboratory experiments of the HPF project (Grimsel Test Site, Switzerland), Journal of Geochemical Exploration, Vol.90 (2006), pp.68-94.

Narita, M., Niibori, Y., Mimura, H., Kirishima, A. and Ahn, J., Sorption behavior of Eu(III) into CSH gel with relatively low Ca/Si ratio <1.0, Proceedings of WM2010 Conference (March 7-11, 2010, Phoenix, AZ), Paper No. 10096 (2010), pp.1-9.

Niibori, Y., Kunita, M., Tochiyama, O., and Chida, T., Dissolution Rates of Amorphous Silica in Highly Alkaline Solution, Journal of Nuclear Science and Technology, Vol.37, No.4 (2000), pp.349-357.

Niibori, Y., Shimoda, S., Tanaka, K., and Tochiyama, O., Understanding the Influence of Spatially Varying Retardation Effect on the Solute Transport, Scientific Basis for Nuclear Waste Management XXVII, Material Research Society, Vol.807 (2004), pp.645-650.

Niibori, Y., Iijima, K., Tamura, N., and Mimura, H., A Calculation of Spatial Range of Colloidal Silicic Acid Deposited Downstream from the Alkali Front, Journal of Power and Energy Systems, Vol. 6, No. 2 (2012), pp.140-150.

Niibori, Y., Funabashi, T. and Mimura, H., Some experiments on sorption behavior of iodide ions into CSH gel under the condition saturated with saline groundwater, Proceedings of Materials Research Society Symposium on Scientific Basis for Nuclear Waste Management XXXVI, Vol.1518 (2013), pp.225-230.

Niibori, Y., Narita, M., Kirishima, A., Chida, T., Mimura, H., Fluorescence emission behavior of Eu(III) sorbed on calcium silicate hydrates as a secondary mineral formed without drying process, Mechanical Engineering Journal, Vol.1, No.4 (2014a), pp.1-7.

Niibori, Y., Usui, H., Chida,T., Mimura, H., A double porosity model to describe both permeability change and dissolution processes, Proceedings of 22nd International Conference on Nuclear Engineering, (July, 7-11, 2014, Prague, Czech Republic), Paper No. ICONE22-30289 (2014b).

Stumm, W. and Morgan, J. J., Aquatic Chemistry (3rd ed.), John Wiley \& Sons (1996).

Sugiyama, D., Fujita, T., Berry, J. A. and Williams, S. J., A study of sorption mechanism onto cement hydrates isotherm measurements, CRIEPI (Central Research Institute of Electric Power Industry) report, T02025 (2003).

Usui, H., Niibori, Y., Tanaka, K., Tochiyama, O., Mimura, H., Fundamental Experiments on Permeability Change of Flow-path by Highly Alkaline Plume, Scientific Basis for Nuclear Waste Management XXVIII, Material Research Society, Vol. 824 (2004), pp.449-454.

Usui, H., Niibori, Y., Tanaka, K., Tochiyama, O., Mimura, H., Permeability Change of Packed Bed with an Amorphous Silicate Mineral by Highly Alkaline Plume, Proceedings of GLOBAL 2005, (October 9-13, 2005, Tsukuba, Japan) Paper No.095 (2005), pp.1-6.

Wakao, N., and Smith, J. M., Diffusion in catalyst pellets, Chem. Eng. Sci., Vol.17 (1969), pp.825-834. 